\title{
Notas
}

\section{Regime político e política exterior: novas aproximações}

\author{
JOSÉ FLÁVIO SOMBRA SARAIVA
}

O seminário internacional "Political Regime and Foreign Policy: A Comparative Approach” (Universidade de Brasília, 5 e 6 de maio de 2003) estabeleceu um novo marco nas relações entre o grupo argentino-brasileiro dedicado ao estudo das relações internacionais e seus pares europeus. Esse seminário, ancorado na experiência de evento internacional anterior dedicado à formação das relações internacionais dos Estados americanos (Universidade de Brasília, agosto de 1994), foi o segundo momento do encontro frutífero dos teóricos e historiadores das relações internacionais da Europa com seus colegas do Cone Sul.

A descoberta mútua provocada pelos encontros realizados, entre 1994 e 2003, na Europa e no Cone Sul, vem abrindo novos enfoques e abordagens teóricas e metodológicas mais plurais. Os grupos vêm desenvolvendo, de forma consistente, projetos internacionais de pesquisa articulados, de interesse comum e de grande fôlego intelectual. Dando continuidade aos esforços de quase uma década empreendidos por Mario Rapoport, Raúl Bernal-Meza, Amado Luiz Cervo, estamos, com esse recente seminário, contribuindo para o estreitamento ainda maior dos contatos entre especialistas brasileiros e argentinos com seus colegas europeus e norte-americanos. A participação do colega alemão Wolfgang Döpcke, que atua há vários anos em forte articulação com esse grupo latino-americano vem alargando o grupo e sua capacidade de incorporação de novos membros.

O seminário internacional de 2003 foi, nesse sentido, um desdobramento natural do esforço de aproximação de diferentes tradições. Elas se cotejam com respeito mútuo, embora divirjam em vários dos tratamentos dados às distintas percepções ontológicas das relações internacionais. O traço horizontal do evento foi dado pelo equilíbrio da participação dos conferencistas das duas regiões e pela elevada contribuição dos textos preparados para a discussão. O modelo aberto do debate - por meio da incorporação de vários especialistas em relações internacionais da Universidade de Brasília, que foram convidados a comentar e debater os textos, como Estevão Chaves de Rezende Martins, Antônio Jorge 
Ramalho da Rocha, Eduardo Viola, Alcides Costa Vaz, Benício Schmidt, Antônio Carlos Lessa e Lúcia Avellar - permitiu que os textos pudessem ser publicamente escrutinados. A presença de cerca de 250 participantes inscritos, entre estudantes, diplomatas e outros profissionais, facilitou a socialização dos temas tratados pelos scholars nos dois dias de debates.

As presenças de Andrew Hurrell, do Nuffield College (Universidade de Oxford), e de Christopher Coker, da London School of Economics and Political Sciences, permitiram conferir a evolução mais recente dos estudos britânicos dedicados ao campo internacionalista. As intervenções de Robert Frank, secretáriogeral da Comissão de História das Relações Internacionais (Comitê Internacional de Ciências Históricas) e diretor do Institut Pierre Renouvin, demonstraram a vitalidade das tradições renouvinianas na moderna historiografia das relações internacionais na França. Da mesma forma, podem-se considerar as presenças de Denis Rolland, da Universidade de Estrasburgo, e de Didier Musiedlak, da Universidade de Paris I. A abertura para a contribuição da Europa oriental se fez com a vinda de Vladimir Kulagin, professor de Relações Internacionais do prestigiado Instituto de Relações Internacionais da MGIMO, a mais reputada universidade de Moscou na área.

Associado ao colega Thomas Skidmore, brasilianista por todos conhecidos, professor da Brown University, o grupo de estudiosos apresentou para o público de especialistas que atendeu ao seminário os resultados de um projeto de pesquisa internacional que se desdobra desde 2001, quando a primeira reunião técnica se fez sob os auspícios do Institut Universitaire de France e da Comissão de História das Relações Internacionais, em Paris. O projeto emanava da percepção de uma lacuna na produção acadêmica dedicada aos temas internacionais que articulasse o grande campo da política externa ao tema dos regimes políticos. Os estudos clássicos de política exterior pareciam desconhecer eventual relação entre esses dois feixes temáticos. Da mesma forma, a literatura atinente ao estudo dos regimes políticos ofereciam poucas pistas acerca das possibilidades de se fazer ilações entre as formas de regimes políticos e eventuais maneiras de condução de políticas exteriores.

Uma segunda preocupação do grupo de pesquisa emanava do fato de que, embora existisse uma certa tradição de vinculação dos regimes democráticos com a idéia de uma política exterior mais cooperativa, essa vinculação não era automática nem poderia ser observada de forma universal. A busca de olhar comparado, por meio da inclusão de experiências empíricas de vários Estados e sociedades, como os casos da América Latina e da África, poderia oferecer novo padrão de interpretação para o estudo das políticas exteriores dos Estados. Daí o esforço que presidiu a pesquisa ao longo dos dois anos ter sido o de avaliar as eventuais conexões entre os dois conceitos na evolução histórica de vários países e regiões da sociedade internacional. 
A terceira preocupação incidia sobre o campo teórico. A eqüidistância com que as teorias sistêmicas de relações internacionais tratavam não apenas o tema das políticas exteriores, mas o de suas relações com outras variáveis, deixava o terreno limpo para incursões novas. O relativo consenso dos realistas clássicos e neorealistas com parte das teorias liberais de relações internacionais no sentido da pouca aplicabilidade das vinculações entre os dois conceitos pareceu, aos olhos dos pesquisadores desse projeto internacional, uma omissão gritante. Isso explica o esforço, particularmente visível nos textos apresentados em Brasília por Hurrell (Political Regimes and Foreign Policies: An Introduction), Frank (Political Regimes and Foreign Policies: Attitudes Towards War and Peace) e meu (Is it Possible to Establish a Causal Nexus Between Foreign Policy and Political Regime?), no sentido de estabelecer o tema no coração da teoria e da historiografia das relações internacionais.

Nas três incursões teóricas, o ponto em comum está no fato de que não é possível admitir uma conexão automática entre democracia e política externa cooperativa nem entre regimes autoritários e vocação externa para a guerra. Da mesma forma, o isolamento de fatores, sem a busca de um caminho de aproximação das múltiplas variáveis, não parece ser a melhor maneira de estudar os casos, os países e as regiões. Ao contrário do que grande parte dos propositores da tradicional "Democratic Peacy Theory”, o esforço foi o de articular de forma mais plural e aberta a relação entre os dois conceitos, em especial no que tange as atitudes em relação à guerra e à paz.

A quarta contribuição do seminário esteve nas conclusões que os conferencistas trouxeram com os estudos de caso das diferentes regiões analisadas. Houve uma gama de contribuições voltadas para casos específicos no tempo, como as de Musiedlak (Fascism, Fascist Regimes and Foreign Policy), Kulagin (In Search of a Causal Nexus between Political Regimes and Foreign Policiy in Post-Soviet Environment) e Skidmore (Brazilian Foreign Policy under Vargas, 19301945: a case of regime type irrelevance). Outras trataram de durações históricas mais dilatadas, como as teses de Coker (The Continuity of American Foreig Policy), Cervo (Political regimes and Brazil's Foreign Policy), Döpcke (Foreign Policy and Political Regime: the case of South Africa), Rolland (Political Regimes and International Relations in the Twentieth-Century: Is There a European Specificity?), Bernal-Meza (Política Exterior de Argentina, Chile y Brasil) e Rapoport (Estado, Regímenes Políticos y Política Exterior Argentina: un abordaje histórico).

Em ambas as abordagens, sejam aquelas encapsuladas no tempo curto ou aquelas voltadas para a construção de categoriais na longa duração, os pesquisadores procuraram enfrentar o desafio intelectual da busca das conexões e padrões que já permitem certas proposições ou generalizações. Destacam-se, entre elas: 
a) a defesa da inclusão, no campo das formulações teóricas das relações internacionais, do problema posto pelo vínculo (ou não) da política exterior com o regime político;

b) a percepção de que há grande diversidade de experiências históricas, especificidades temporais e realidades regionais que devem ser levadas em conta no tratamento das relações entre regimes políticos e políticas exteriores;

c) a idéia da necessidade de inclusão do fator regime político no conjunto de fatores que operam - alguns de forma bastante mais decisiva que os problemas advindos dos tipos de regime ou das mudanças de regime político - na base da evolução das políticas exteriores dos Estados;

d) a preocupação com a visibilidade do vínculo necessário que deve ser estabelecido entre as políticas exteriores, os regimes políticos e as características estruturais e conjunturais dos Estados;

e) a exploração das situações divergentes dos casos nos quais há relevância explícita das formas de regime político com o perfil da política exterior (caso dos fascismos europeus do entreguerra) com aqueles nos quais há baixíssima relevância explícita entre a forma de regime político e a continuidade na política externa (caso brasileiro);

f) a vontade em ampliar o debate em torno das relações entre a sociedade internacional e as formas de regime político para avaliar até que ponto não é a forma da própria sociedade internacional que cria as condições para que certas formas de regimes políticos possam subsistir (casos como o da sociedade internacional européia do século XIX bem como o dos regimes políticos autoritários na América Latina no período da Guerra Fria).

g) a proposta de revisão de certas ilações reducionistas propostas pela "Democratic Peace Theory", em especial no que se refere a seu apego à universalização de um único modelo democrático.

À guisa de conclusão, deve-se registrar que o grupo de pesquisa multinacional não encerrou seus trabalhos. Os textos apresentados e os debates realizados no Seminário de Brasília, bem como o processo em curso de revisão e adaptação dos textos preparados, serão a base para o lançamento de obra inédita, prevista ainda para o ano em curso de 2003, com impacto sobre a teoria e a historiografia das relações internacionais. Ademais, o sucesso do evento de Brasília aconselha iniciar de imediato novos projetos internacionais de pesquisa, mantendo o ritmo alegre e fecundo dessa conexão europeu-argentino-brasileira. 